\title{
La creciente importancia de los debates antiespecistas en la teoría política contemporánea: del bienestarismo al abolicionismo
}

\author{
The growing importance of antispeciesist debates in contemporary political \\ theory: from welfarism to abolitionism
}

\author{
RAFAEL VÁZQUEZ \\ Universidad de Granada
}

ÁNGEL VALENCIA

Universidad de Málaga

\section{Cómo citar/Citation}

Vázquez, R. y Valencia, A. (2016). La creciente importancia de los debates antiespecistas en la teoría política contemporánea: del bienestarismo al abolicionismo. Revista Española de Ciencia Política, 42, 149-166. Doi: http://dx.doi. org/10.21308/recp.42.06

\section{Resumen}

Los perfiles del comportamiento ético de los seres humanos hacia los animales no humanos han cobrado una progresiva relevancia pública en los medios de comunicación durante las últimas décadas. Las cuestiones relacionadas con el maltrato animal, la explotación industrial de especies comestibles o los términos de la relación privada con animales domésticos parecen estar más que nunca en el centro del debate público. Esta novedosa situación nos induce a la reflexión en torno a las nuevas relaciones establecidas con los animales no humanos, asuntos que hasta hace pocas décadas resultaban marginales y con escasas referencias en la teoría política contemporánea.

En esta nota de investigación se exponen las teorías clásicas y las más actuales en torno al debate sobre los derechos animales, destacando algunos elementos como los siguientes: qué entendemos por especismo y antiespecismo; hasta qué punto es posible conferir derechos a los animales no humanos y, sobre todo, qué posturas y debates encontramos en el seno del movimiento animalista, fundamentalmente entre los defensores del proteccionismo bienestarista para los no humanos y los partidarios de un enfoque abolicionista de la propiedad.

Palabras clave: especismo, antiespecismo, derechos animales, teoría política, vegetarianismo, veganismo, bienestarismo, abolicionismo 


\begin{abstract}
The profiles of human beings' ethical behavior towards non-human animals have gained increasing public relevance in the media over the past decades. Issues related to animal abuse, industrial exploitation of edible species or the terms of the private relationship with pets seem to be, more than ever before, at the centre of public debates. This new situation leads us to reflect around the newly established relationships with nonhuman animals; issues that have remained marginal and worthy of few references in contemporary political theory until very recently.

This research note discusses the classic and latest theories on the debates over animal rights theories, highlighting some elements such as: what is meant by speciesism and antispeciesism; to what extent may rights be granted to non-human animals; and above all, which are the positions and debates within the animal movement, mainly between advocates of welfarist protectionism for nonhumans and supporters of an abolitionist approach to property.
\end{abstract}

Keywords: speciesism, antispeciesism, animal rights, political theory, vegetarianism, veganism, welfarism, abolitionism.

"Al verme sentado frente a usted, Pedro el Rojo, lo oigo hablar y bebo a su salud -usted podrá tomarlo como cortesía o no, pero es la pura verdad-, me olvido por completo de que es usted un chimpancé. Solo poco a poco, cuando consigo volver a la realidad, los ojos me indican de quién soy huésped».

(Franz Kafka, Informe para una academia, 1917)

\title{
INTRODUCCIÓN. EL GIRO ANIMALISTA
}

Los perfiles del comportamiento ético de los seres humanos hacia los animales no humanos han cobrado una progresiva relevancia pública en los medios de comunicación durante las últimas décadas. Las cuestiones relacionadas con el maltrato animal, la explotación industrial de especies comestibles o los términos de la relación privada con animales domésticos parecen estar más que nunca en el centro del debate público. La reciente relectura antitaurina de la pintura de Goya, el reconocimiento del trabajo heroico de canes en catástrofes naturales, las penas de cárcel para quienes maltratan mortalmente a animales no humanos, por no hablar de la enorme y paulatina influencia de nuevos -y también rescatados- hábitos alimenticios veganos/vegetarianos, o la creciente presencia electoral del Partido Animalista Contra el Maltrato Animal (PACMA) en España, así lo atestiguan.

Desde el ámbito académico, la filosofía antiespecista afirma que nos encontramos hoy día en el camino hacia un cambio de paradigma, la construcción de una nueva hegemonía no especista. De forma creciente afloran debates que no habían tenido apenas lugar antes y que se empiezan a establecer y consolidar en la esfera pública, desde la sociedad civil, los medios de comunicación o los parlamentos hasta el mundo 
académico, donde las disquisiciones no han dejado de crecer desde el último cuarto de siglo Xx.

El denominado "giro animalista» en la investigación académica ha logrado transitar desde las ciencias naturales hasta disciplinas más humanistas y a las ciencias sociales, como la psicología, la filosofía, la antropología, la ciencia política y la sociología, dejando al tiempo una reseñable impronta en la literatura, la historia, los estudios críticos y culturales, así como también en la geografía, el feminismo y hasta en la teoría queer (Best, 2009). Los estudios sobre "animal rights» no han dejado de evolucionar desde la segunda mitad de los años setenta, ofreciendo perspectivas y aproximaciones cada más complejas, refinadas y multidisciplinares. No solo se trata de un nuevo objeto de estudio en el ámbito académico, sino de una temática que por su propia naturaleza pretende ser transformadora social y políticamente y que resulta eminentemente crítica con los saberes naturalizados y, por ende, contrahegemónica.

\section{ESPECISMO COMO HEGEMONÍA ANDROCÉNTRICA}

Si bien el término «especismo" aparece por vez primera con Richard Ryder en 1970, entendido como una discriminación moral basada en la diferencia de especie animal, la primera obra académica en la que se aprecia dicho término es Animals, men and morals: an inquiry into the maltreatment of non-humans, coordinado por Stanley y Roslind Godlovitch y John Harris en 1971. En 1975 el concepto empezaría a difundirse ampliamente con Peter Singer y su ya clásica obra Animal liberation: a new ethics for our treatment of animals. Un año más tarde, Andrew Linzey vuelve a presentar críticamente el concepto desde un punto de vista religioso en su Animal rights: a Christian perspective.

El especismo podría ser entendido como una consideración o tratamiento injustificadamente desventajoso de aquellos que no pertenecen a una o varias especies particulares por el solo hecho de pertenecer a otra especie (Singer, 1975: 22; Horta, 2010: 5). Por lo general, al usar el término especismo tendemos a pensar en la discriminación llevada a cabo por sujetos humanos hacia animales no humanos o hacia cualquier otra especie natural. No obstante, el especismo incluiría de igual manera cualquier discriminación entre especies, lo que implicaría plantear discriminaciones entre especies no humanas. Esto supondría, por ejemplo, que no deberíamos establecer una diferenciación en la consideración dada a los animales domésticos frente a los no domésticos en cuanto a su estatus moral si no queremos caer en posiciones especistas.

La discriminación animal, el especismo, ha estado presente a lo largo de toda la historia. Aristóteles sostenía en la Política que «las plantas existen para los animales, y los demás animales, en beneficio del hombre; los domésticos para su utilización y su alimentación, y los salvajes -si no todos, al menos la mayor parte de ellos-, con vistas a la alimentación y a otras ayudas, para ofrecer tanto vestidos como otros utensilios». Las religiones, especialmente las monoteístas, frecuentemente han minusvalorado la posición de los animales dentro de la esfera de la existencia, otorgándoles un puesto de sim- 
ple servicio al hombre. En el siglo xviI, Descartes afirmaba que los animales no eran más que autómatas que no poseían alma ni conciencia, desprovistos de entendimiento, debido a lo cual no podrían sentir dolor, placer ni emociones. Para el liberalismo posterior del siglo XVIII y XIx, los animales quedaban igualmente excluidos de la comunidad moral. Si bien, tal y como expresaba Kant, no debiéramos causarles daño de forma gratuita, y puesto que no disponen de intereses moralmente significativos, los humanos no tenemos ningún tipo de obligación directa respecto a los no humanos.

El paradigma humanista actual, en continuidad con la misma línea especista, sostiene que solamente los seres humanos son miembros de la comunidad moral. Como puede observarse, dicho paradigma contiene un aspecto inclusivo -todos los seres humanos merecen igual protección- y uno exclusivo -solo los seres humanos tienen ese estatus- (Cavalieri, 2003). Muchas de estas teorías apelan a la falta de conciencia en los animales y al uso exclusivo de lenguaje en los seres humanos (Frey, 1980; Leahy, 1993) o a la singular relación de poder que los humanos mantienen con otras especies (Goldman, 2001). La mayor parte de las posiciones especistas asumen, de una u otra forma y por mera definición - «parece ser evidente para todos»- que no por argumentación, que los humanos son superiores y, por ende, detentan un mayor valor que el resto de animales (Machan, 2004; Posner, 2004).

El especismo ha sido percibido como parte de un antropocentrismo o androcentrismo mucho más extenso, que igualmente discrimina a mujeres, minorías étnicoraciales o clases sociales bajas. Es por ello, que el especismo haya recibido importantes críticas desde posiciones feministas (Adams, 1991) o desde posiciones fuertemente opuestas a los sistemas de dominación capitalistas (Young, 1990). También la lucha contra el racismo ha señalado que, al igual que los argumentos prorracistas aceptan la existencia de un orden natural con razas superiores, el especismo plantea de forma paralela la existencia de una especie superior a la cual las demás quedan supeditadas (Spiegel, 1996). Puede, pues, afirmarse que las posturas especistas poco difieren de aquellas que justifican el racismo, el sexismo, la homofobia, el clasismo o el cognitivismo en el seno de la especie humana.

Este especismo supone la utilización cotidiana y sistemática de animales no humanos por parte de los humanos partiendo de una premisa raramente cuestionada: la «propiedad natural» que se ejerce sobre ellos. Esto tiene lugar en múltiples acciones que van más allá de su consumo como alimentos, como la vestimenta, la experimentación o el entretenimiento.

\section{EL ANTIESPECISMO COMO UNA TEORÍA CONTRAHEGEMÓNICA DE LOS DERECHOS ANIMALES}

El antiespecismo como consideración moral es una oposición a la discriminación especista en todos los ámbitos señalados, basada en la idea de que solo la cualidad de sentir, de sufrir y disfrutar resulta relevante a la hora de determinar quién merece consideración y respeto. Al igual que respetamos a los seres humanos independientemen- 
te de su sexo, raza o capacidad cognitiva, debemos respetar a los demás animales independientemente de su especie. Dentro de la enorme variedad de temas tratados, las investigaciones sobre el antiespecismo se han centrado fundamentalmente en la cuestión de los derechos animales, en el controvertido debate en torno al bienestarismo frente al abolicionismo de propiedad y explotación, y en la presentación de las teorías sobre derechos animales desde multitud de perspectivas y disciplinas. Aquí nos centraremos en exponer los componentes ideológicos de las mismas desde el punto de vista del pensamiento político y la teoría política contemporánea.

\section{¿Derechos para los animales no humanos?}

Desde un plano jurídico los animales no humanos gozan actualmente de ciertos derechos de protección en muchos ordenamientos. De forma creciente en los últimos años, y con el paralelo aumento de una mayor conciencia humanitaria hacia el resto de animales, muchos parlamentos han aprobado cierta legislación proteccionista. Ahora bien, ¿se puede hablar propiamente de derechos para los animales no humanos?

La cuestión de los derechos animales es, sin duda, la más controvertida en el ámbito del animalismo, puesto que no existe un aplaudido consenso en torno a qué tipo de derechos nos estamos refiriendo (legales, morales), qué propiedad de los mismos o de los propios seres humanos tomamos como referencia para otorgar derechos -la capacidad de sentir, de sufrir, de ser conscientes, de imaginar una vida futura...- o el alcance de estos -limitación del sufrimiento, protección de las condiciones de vida, derecho a la vida, derecho a la participación en la propia ciudadanía como se propone desde el Proyecto Gran Simio...- (Waldau, 2011).

El punto de partida es, por lo general, el mismo: si la atribución de derechos se basa en una cierta analogía entre propiedades intrínsecas humanas y las de otros seres, tales como sentir dolor, deberíamos ser más propensos a conceder derechos a aquellos que sufren como nosotros. Así, para Jeremy Bentham, el solo hecho de que los animales puedan sentir agonía y sufrimiento les otorgaría un derecho fundamental a la vida, a no ser esclavizados ni torturados. En la misma línea utilitarista como veremos más adelante, Peter Singer se refiere al concepto de "persona», como todo aquel ser vivo con capacidad para anticipar su ser en el pasado y en el futuro, lo que daría cabida si bien no a todos los animales no humanos sí a algunos de ellos, como la mayoría de los mamíferos. Todos ellos tendrían el derecho inexcusable a la vida (Singer, 1975). Por su parte, Tom Regan habla de derechos morales para los animales no humanos, derechos intrínsecos con independencia de la racionalidad o no de los mismos. Esto es, el hecho de que todas las especies tengan un valor inherente en sí (sujeto-de-una-vida) les proporcionaría el derecho a no ser tratado como un mero medio para los fines de otro (Regan, 1983). En el mismo sentido, Paola Cavalieri insiste en que las diferencias biológicas no pueden conducirnos a diferenciaciones morales (Cavalieri, 2003). Desde el criterio de la autonomía práctica, Steven Wise justifica que todos los seres que posean un yo, que actúen intencionalmente y que posean deseos (primates, delfines o 
elefantes) debieran ser titulares de unos derechos básicos entre los que se incluyen el no ser utilizados como alimentos o para la investigación (Wise, 2000). Por su parte, Gary Francione parte del presupuesto de que mientras que los animales no humanos sean considerados desde la perspectiva de propiedad de los humanos, cualquier protección legal de los mismos es especista e interesada y no podríamos hablar en ningún caso de derechos animales (Francione, 1995).

Otro de los elementos del debate es si todos los animales deberían contar con los mismos derechos. Aquí los planteamientos oscilan entre la distinción morfológica y la complejidad biológica de los mismos y aquellos que dividen la comunidad animal entre los animales domésticos o de trato directo y la fauna salvaje. Estos últimos, los animales silvestres, son generalmente percibidos desde el animalismo como comunidades soberanas con derecho a protección contra la colonización, la invasión y la dominación, y por tanto con derechos distintivos de aquellos otros que conviven de ordinario con el ser humano (Donaldson y Kymlicka, 2011).

Por lo demás, siempre permanece el problema principal a la hora de hablar de derechos animales: quién confiere estos derechos. Puesto que se trata de una discusión abierta y encontrada entre humanos (si bien en relación a animales no humanos) deberíamos admitir que, en cualquier caso, se trata de un acto antropocéntrico, puesto que los términos del debate, ya sean los de los animalistas abolicionistas o los defensores de la superioridad total de los humanos, son términos creados y discutidos entre animales humanos. En última instancia, son los seres humanos quienes otorgan o reconocen derechos a los animales.

\section{BIENESTARISMO Y ABOLICIONISMO EN LA DEFENSA DE LOS DERECHOS ANIMALES}

\section{Bienestar animal y derechos animales}

La práctica totalidad de la legislación de protección animal confiere, como hemos visto, derechos de protección o de trato justo, si bien no estaríamos hablando de derechos inalienables de la especie humana como el derecho a la vida, sino de medidas legales para evitar el sufrimiento innecesario aceptando en cualquier caso el uso de los mismos en favor de la especie humana. Uno de los argumentos más extendidos a favor del bienestarismo desde el punto de vista religioso es la idea de que infligir un trato degradante a los no humanos nos predispone a una mayor violencia entre humanos, al considerar que se degrada la moralidad entre humanos y se fomenta la insensibilidad moral y la crueldad entre los mismos. Así, las posturas en las religiones principales han oscilado entre la protección y la afinidad para con los animales no humanos y el sacrificio y consumo diversificado de los mismos (Perlo, 2009).

$\mathrm{Al}$ margen de la preocupación expresada por muchas religiones en torno al sacrificio respetuoso de los animales, esta codificación bienestarista orientada a limitar el dolor de los mismos en los ordenamientos no comienza sino en la década de los años 
veinte del siglo XIX, si bien ya desde 1635 en Irlanda se aprobaron algunas leyes al efecto. La creación de la Society for the Prevention of Cruelty of Animals en 1824 es buen ejemplo de institucionalización de ello. La Declaración Universal de los Derechos Animales de 1977 expone en los apartados a y b del artículo 2 que «todo animal tiene derecho al respeto y que el hombre, como especie animal, no puede atribuirse el derecho de exterminar a los otros animales o de explotarlos, violando ese derecho». Es por ello, como se sigue en el apartado c, que «todos los animales tienen derecho a la atención, a los cuidados y a la protección del hombre». En el Reino Unido, las denominadas Cinco libertades del bienestar animal, aprobadas en 1979 por el Farm Animal Welfare Council, incluían estar libres de hambre y sed, de incomodidad, de dolor, lesiones y enfermedades, la libertad de expresar un comportamiento normal así como la libertad de estar libres de miedo y angustia.

En España, la legislación proteccionista es mucho más reciente. La materia está fundamentalmente regulada por el Real Decreto 53/2013, de 1 de febrero, por el que se establecen las normas básicas aplicables para la protección de los animales utilizados en experimentación y otros fines científicos, incluyendo la docencia. La evolución ha sido muy notable desde principios del siglo pasado hasta la actualidad (Pérez, 2012; Baltasar, 2015). De igual forma, el artículo 33 del Código Penal de 1995, modificado por la LO 1/2015, ha introducido nuevas penas de inhabilitación para la tenencia de animales y el ejercicio de profesiones relacionadas con animales. La misma reforma ha establecido penas más severas en el artículo 337 para el que por cualquier medio o procedimiento maltrate injustificadamente a un animal, causándole lesiones que menoscaben gravemente su salud o le sometan a explotación sexual.

Sin embargo, el bienestarismo, como vamos a desarrollar a continuación, no casa en la mayor parte de las ocasiones con las reivindicaciones animalistas antiespecistas que consideran, por lo general, central y no discutible el derecho a la vida de los animales no humanos. La principal crítica vertida sobre el bienestarismo es que, pese a los intentos de mejorar las condiciones de vida de muchos animales, estos siguen siendo explotados por intereses varios (alimentación, vestimenta, ocio...), puesto que se parte del presupuesto de la propiedad de los mismos en manos humanas (Francione, 1995). Mientras los bienestaristas responden a una visión antropocéntrica del mundo, defendiendo la utilización y el trato «humano» de los animales no humanos, los abolicionistas son, para muchos, los únicos que podrían reconocerse como genuinos antiespecistas, si bien aquí la amalgama de posturas en el seno de los mismos es significativamente amplia. Frente al «bienestar» de los animales, estos vendrían a proponer verdaderos «derechos animales».

\section{LOS DEBATES ANTIESPECISTAS EN LA TEORÍA POLÍTICA}

Con el primer despliegue de los debates animalistas en el siglo Xvin y las primeras décadas del XIX, aparecen las primeras reflexiones contemporáneas sobre los «animal rights». Así nos encontramos con las figuras de Humphry Primatt o Arthur Broome 
-fundador en 1824, junto con Lewis Gompertz (autor de Fragments in defence of animals), de la Society for the Prevention of Cruetly to Animals- o de algunos cristianos reformados como George Angell, quien en 1868 funda la Massachusetts Society for the Prevention of Cruelty to Animals, sin perjuicio de que tales reivindicaciones se formulen en función no tanto de los «derechos animales» sino, por ejemplo, de algunas emociones como la compasión o el humanistarismo hacia unas denominadas bestias a las que ya no se considerarán como máquinas (tal y como planteaba el modelo cartesiano), si bien en todo caso, la razón o el derecho que se les reconozca en modo alguno será suficiente para conmensurarlas mínimamente con los animales humanos.

Sin embargo, el rápido desenvolvimiento de la revolución darwinista, a partir de 1859 -y, sobre todo, tras la publicación del El origen del hombre en 1871- ocasionaría la conformación de un segundo despliegue animalista que podía ya presentar, ahora con una mayor incidencia y preocupación, la temática de los «derechos de los animales». De este período proceden, por ejemplo, figuras como Frances Power Cobbe y su Darwinism in Ethics (1872), Edward Byron con su The right of an animal. A new essay in Ethics (1879) o Henry Stephen Salt con Animal rights considered in relation to social progress (1892). Este último, junto con otras destacadas personalidades intelectuales de su época, llegaría a participar en 1891 en la Conferencia de la Sociedad Vegetariana Internacional celebrada en Londres a la que también asistiría el propio Gandhi, recién llegado al Reino Unido entonces. Se trata de reivindicaciones directas de los «derechos de los animales», vistos ahora, en tanto que taxones zoológicos, en plena continuidad genética con la especie humana.

Ya en el siglo xx, y concretamente en la década de los sesenta, tras un largo período de desinterés y esterilidad argumentativa en torno a la cuestión de los derechos animales, la temática del animalismo reaparece bajo la forma de un tercer despliegue animalista. Así, en 1971, Stanley y Roslind Godlovitch y John Harris publicarían Animals, men and morals, uno de los primeros «trabajos serios sobre los derechos de los animales desde Los derechos de los animales considerados en relación al progreso social de Henry S. Salt» (Ryder, 2000). Esta obra, de autoría colectiva, es la primera donde se examinan tanto los argumentos a favor y en contra del especismo, como aquellos en torno a la relevancia moral de las capacidades cognitivas y los que proponen la sintiencia como criterio para la consideración moral.

En 1975 sale a la luz el clásico Animal liberation, de Peter Singer. Los años en los que Singer escribe Liberación animal son los años en los que los que se consolidan los estudios sobre el lenguaje y la cultura de los animales y sobre la cognición animal, pero también, y esto es importante hacerlo notar, los años en los que las reivindicaciones de los «animal rights» cobran una pujanza renovada con la Declaración Universal de los Derechos de los Animales en 1977 o la fundación del primer Frente de Liberación Animal en 1976. La idea central de la obra de Singer es que los intereses de todos los individuos que pueden sufrir y disfrutar deben ser igualmente considerados. Esta idea se deriva de la combinación de otras dos que no suelen resultar tan controvertidas. En primer lugar, la fuerte intuición, ampliamente compartida, sobre la consideración igualitaria de todos los seres humanos. Y en segundo lugar, la necesidad de ser 
consistente en el razonamiento moral, es decir, de no incurrir en contradicciones cuando pensamos. La aceptación de la primera idea es lo que nos lleva a rechazar que se asigne una importancia diferente a los intereses de los individuos con base, por ejemplo, en ciertas características biológicas como el sexo o el color de la piel. De forma similar, puesto que la pertenencia a una determinada especie tampoco afecta a cuán importantes son los intereses de los individuos, tampoco debemos aceptar que esta sea una característica moralmente relevante. Así, la consideración desigual de intereses basada en la especie de los individuos debe, por consistencia, ser rechazada en tanto que una forma más de discriminación —especismo—, tan carente de justificación como el racismo o el sexismo.

En 1981, Bernard Rollin publica Animal rights and human morality, donde plantea que lo relevante para tener en consideración moral a un individuo es que tenga necesidades, deseos, objetivos, propósitos y, en general, intereses. Por ello, defiende que es injusto discriminar a los animales no humanos si no encontramos diferencias moralmente relevantes entre ellos y los humanos. Argumenta que la existencia de sistema nervioso es causa necesaria y suficiente para que un individuo tenga intereses, por lo cual los animales no humanos tienen intereses (Rollin, 1981).

El filósofo estadounidense Tom Regan es uno de los mayores especialistas en la teoría de derechos animales. En su clásico The case for animal rights, planteó una teoría de corte deontológico partiendo de los conceptos de «valor inherente» y de ser «sujeto-de-una-vida» como criterios moralmente relevantes y suficientes a la hora de decidir qué seres son portadores de derechos y cuáles no. Ser sujeto-de-una-vida es ser un individuo cuya vida se caracteriza por poseer algunas capacidades específicas: tener creencias y deseos, tener percepciones, memoria y sentido del futuro (incluyendo su propio futuro), tener una vida emocional junto con la capacidad de sentir placer $y / o$ dolor, tener intereses y preferencias relativas al bienestar individual, ser capaz de actuar con el objetivo de satisfacer deseos y metas, poseer una identidad psicofísica en el tiempo, etc. (Regan, 1983: 243). Todo sujeto-de-una-vida y los animales no humanos lo son, tienen un valor inherente, es decir, poseen un valor más allá de lo útil que sea para el resto de los seres (Regan, 2004).

En Morals, reason, and animals, Steve Sapontzis argumenta por su parte que poseer capacidades cognitivas complejas es innecesario para ser agente moral, que hay animales que son agentes morales, y que existe una continuidad entre humanos y animales en lo relativo a la moral. Afirma que los animales pueden ser considerados agentes morales y, por tanto, virtuosos. En esta obra, señala varios motivos para respetar los intereses de los animales como desarrollar nuestra personalidad moral, reducir el sufrimiento o hacer del mundo un lugar más justo (Sapontzis, 1987).

Beyond prejudice: the moral significance of human and nonhuman animals, escrito por Evelyn Pluhar, da un paso sustantivo en la defensa de los derechos animales y de las capacidades emocionales cognitivas a partir de la idea de «significancia moral» y al rechazar los argumentos antropocéntricos empleados en defensa del especismo. Señala que la crítica al especismo antropocéntrico y a que lo relevante es «ser persona en sentido pleno» (implicando esto la posesión de ciertas capacidades cognitivas) está basada 
en dos argumentos: la diferenciación debe estar basada en factores moralmente relevantes, lo cual no ocurre por pertenecer a una especie y hay humanos que no satisfacen los criterios defendidos por los antropocentristas (Pluhar, 1995).

En su estudio Taking animals seriously: mental life and moral status, David DeGrazia tiene en cuenta varias razones sobre la consideración moral igualitaria y su reconocimiento a los animales no humanos, analizando la literatura más relevante. Presenta y evalúa evidencias y argumentos para considerar que varios animales no humanos poseen la capacidad de tener experiencias, y de poseer deseos, emociones, creencias y otros estados mentales. Examina si esto puede ser una base para una definición común de bienestar para los animales de distintas especies y para establecer criterios útiles a la hora de considerar comparativamente el peso de estos (DeGrazia, 1996).

En Frontiers of justice, Martha Nussbaum presenta una teoría que afirma que los animales no solamente merecen consideración moral directa como había reivindicado Peter Singer, sino que debieran ser titulares de derechos como ha planteado reiteradamente Tom Regan. En palabras de Nussbaum, «la emoción de la compasión supone pensar que otra criatura está sufriendo apreciablemente y que tiene muy poca (o ninguna) culpa de ese sufrimiento. Lo que no implica es creer que alguien es el culpable de dicho sufrimiento». El problema de que los deberes humanos hacia los animales se limitaran a deberes de compasión consistiría entonces en la omisión de un elemento esencial: la culpabilidad (Nussbaum, 2006: 351).

\section{LA CRÍTICA ABOLICIONISTA AL BIENESTARISMO PROTECCIONISTA}

Sin embargo, algunas de las posiciones antiespecistas más reconocidas y señaladas, entre las que destacan las de Gary Francione, resultan fuertemente críticas con muchos de los planteamientos sensocentristas anteriores. Francione es el autor más destacado y reconocido del enfoque abolicionista, que plantea derechos animales frente a mera legislación de protección. Su posición es contraria a la de los bienestaristas -muchas veces encubiertos bajo posiciones utilitaristas, en palabras de Francione- y en gran medida a la de muchos ecologistas con sus fórmulas empleadas para la sostenibilidad medioambiental. El sobresaliente debate que mantiene con Robert Garner ejemplifica claramente los argumentos encontrados de ambas posiciones (Francione y Garner, 2010).

En Introduction to animal rights: your child or the dog?, Francione expone que sufrimos una esquizofrenia moral hacia los animales pues consideramos inmoral hacerlos sufrir, pero adoptamos un estilo de vida incoherente con esto. Nos preocupamos por algunos animales, pero usamos y matamos a otros. Su punto de partida rechaza que los animales sean propiedades. Critica el utilitarismo de Bentham, considerando a Singer como el proponente actual del mismo, y defiende que dar importancia moral a los intereses de los animales implica no usarlos para nuestros fines de una manera en que no usaríamos a seres humanos con diversidad funcional intelectual o sin hogar, principio de igual consideración a extender a todos los individuos sintientes (Francione, 
2000). Para Francione los animales no podrán en todo caso ser considerados como cosas - por ejemplo a título de robots, tal y como señala el propio Francione argumentando contra humanistas cartesianos al estilo de Peter Carruthes o R. G. Frey- y solo resta incorporarlos con pleno derecho a la categoría de persona. Consideraciones como esta, lo sitúan en una posición claramente contraria a lo que él mismo llama «nuevo bienestarismo", puesto que este planteamiento bienestarista ni siquiera impugnaría la «propiedad» sobre las personas animales. Para Francione y los abolicionistas el bienestarismo no dejaría de tener como soporte una concepción especista y antropocéntrica del mundo en la que el uso y hasta la explotación de los no humanos sería aceptada siempre y cuando bajo unos supuestos de limitación o refinamiento del uso de dicha explotación.

En su libro Animals as persons. Essays on the abolition of animal exploitation desarrolla estas y otras ideas y reafirma esta posición al entender que no deberíamos perseguir reformas bienestaristas tradicionales (Francione, 2009). Por el contrario, mucho más consecuente sería propugnar cambios abolicionistas que paulatinamente erradicasen el estatus de propiedad de los no-humanos y que reconozcan que los no-humanos tienen valor inherente. Para Francione, mientras los animales sean propiedades, nunca habrá una valoración significativa de los intereses humanos y no-humanos, así como no había tal valoración entre los intereses de los esclavos y los de los dueños de los esclavos (Francione, 1995, 2009).

En su último libro hasta el momento, Animal rights: the abolitionlist approach, Gary Francione y Anne Charlton proponen una suerte de manifiesto en el que recogen y resumen el ideario actualizado del pensamiento abolicionista (Francione y Charlton, 2015) y que podría quedar resumido en seis propuestas.

1. Los abolicionistas mantienen que todos los seres sintientes, humanos y no humanos, tienen un mismo derecho, el derecho básico a no ser tratados como propiedad de otros.

Esto implicaría que no podemos apropiarnos de su carne, de su piel ni de cualquier producto derivado de los mismos. Frente al parecer de los bienestaristas, desde el punto de vista abolicionista, el valor moral otorgado a los humanos y no humanos sin distinción nos alejaría de la concepción de los mismos como propiedad. Ningún miembro de la comunidad moral debe servir para beneficio involuntario de cualquier otro. Si esto es aplicable con claridad en el caso de los humanos para condenar cualquier tipo de esclavitud humana, también debiera serlo para el caso de los no humanos. Esto es, debiéremos reconocer que todos los seres sintientes son iguales en el propósito de no ser utilizados exclusivamente como fuentes de recursos para los humanos (Francione y Charlton, 2015: 17-20). Por lo tanto, cualquier pretendido trato "humanitario" por parte del proteccionismo bienestarista, pero que perpetúe la condición de «cosa al servicio de» de los no humanos es injustificable desde el abolicionismo. En el mismo sentido en que siguiendo a Rawls no 
podemos considerar a ningún ser humano como medio para nada, este en un claro contraargumento contra las posiciones utilitaristas.

2. Los abolicionistas mantienen que el reconocimiento de este derecho básico implica que debemos abolir y no meramente regular la institucionalizada explotación animal, por lo que los abolicionistas no debieran apoyar las campañas de reforma bienestaristas ni en su conjunto ni en relación a cuestiones concretas. El reconocimiento del derecho de los animales a no ser utilizados como propiedad de otros, vacía de sentido para los abolicionistas la mera regulación -para hacerla más «humana»- de la explotación de animales no humanos. Las campañas bienestaristas, llevadas a cabo por múltiples plataformas de la sociedad civil y por la mayor parte de los partidos animalistas, carecerían de sentido, pues no llevarían sino a perpetuar esta institucionalizada violencia contra los no humanos. Del mismo modo, resulta inaceptable desde este prisma aceptar cualquier campaña benefactora de la explotación animal que pudiera establecer cualquier taxonomía entre formas de explotación aceptables frente a otras inaceptables. Aquí, es claro que todas ellas deben ser rechazadas como especistas (Francione y Charlton, 2015: 39-42).

3. Los abolicionistas mantienen que el veganismo es un punto de partida y que la educación vegana creativa y no violenta debe ser la piedra angular en la defensa de los derechos animales. El veganismo es incompatible con el antropocentrismo moral y con el bienestarismo. No acepta el prejuicio del especismo ni tampoco la ecuación utilitarista de aumentar el bienestar y reducir el sufrimiento. El veganismo, por tanto, defiende que los demás animales deben ser considerados y respetados como personas, y por tanto no debemos cosificarlos como recursos para nuestro propio beneficio ni instrumentalizarlos a nuestro favor.

Para la psicóloga Melanie Joy, en un reciente libro convertido ya en bestseller, Por qué amamos a los perros, nos comemos a los cerdos y nos vestimos con las vacas, antes de plantear la definición y el uso de dietas libres de productos animales, convendría plantearse el porqué de la continuidad y la justificación del consumo de carne. Para Joy, el maltrato animal y el carnismo se han asentado no solo en la consideración de la superioridad de la especie humana, sino también en el apartamiento de las emociones a través de una disonancia cognitiva, haciendo invisible de esta forma el sufrimiento y aceptando la lógica especista a través de la insensibilidad, la ausencia de empatía, la lejanía con el padecimiento y el haber cosificado e instrumentalizado racionalmente la imagen de los animales no humanos (Joy, 2013; Lara y Campos, 2015). Esta disonancia cognitiva puede entenderse como la tensión o incomodidad que percibimos cuando mantenemos dos ideas contradictorias o incompatibles, o cuando nuestras creencias no están en armonía con lo que hacemos. Como plantea la psicóloga norteamericana, la pervivencia del carnismo, y hasta su «naturalización», se apoya en toda una serie de estrategias y mecanismos no exentos de intereses corporativos ni de manipulaciones. 
Existe todo un debate en torno a la congruencia del vegetarianismo como tipo de dieta vinculada al consumo de huevos, leche y otros productos de origen animal como la miel. Puesto que la consecución de estos otros productos al margen de la carne, podría -y frecuentemente lo hace-implicar algún tipo de explotación animal, el vegetarianismo no tendría sentido sino es alejado de cualquier consumo de origen animal. Siendo así, el vegetarianismo estricto no sería sino la denominación de la dieta del veganismo, un estilo de vida mucho más holístico, algo así como una manera de estar en el mundo. Como proponen Francione y Charlton, desde posiciones abolicionistas el veganismo no sería una opción, sino un imperativo moral, por lo que cualquier movimiento que buscase justicia social para los no humanos debería promover inexcusablemente el veganismo como punto de partida (Francione y Charlton, 2015: 94). Como el propio Gary L. Francione ha planteado, «en una sociedad saturada de explotación animal, es extremadamente difícil -quizás imposibleno ser al menos indirectamente cómplice de esta explotación como consumidores. Pero sin embargo podemos estar seguros de que si no somos veganos, somos ciertamente explotadores» (Francione y Charlton, 2013). Esto es, al contrario de lo que proponen algunos bienestaristas -Peter Singer afirma que podemos ser "omnívoros conscientes» y explotar éticamente a los animales si, por ejemplo, elegimos comer animales «libres de jaulas», quienes han sido criados y matados de una manera relativamente "humanitaria» (Singer y Mason, 2006: 81-169)-, que el antiespecismo abolicionista plantea que existe veganismo y explotación animal sin posibilidad de una tercera opción.

4. El enfoque abolicionista vincula moralmente a humanos y no humanos en base a la sintiencia y no en relación a ningún elemento cognitivo. Esto implicaría que todos los seres sintientes deben ser vistos como iguales y no ser considerados como fuentes de aprovechamiento por otros. En la Encyclopedia of Animal Rights and Animal Welfare, editada por Marc Bekoff y Carron A. Meaney (1998), estos autores entienden la sintiencia o el sensocentrismo como un sistema de valores y principios que se centran en la capacidad de sentir. Dicho de otra forma, el sensocentrismo define como lo más valioso a ese «alguien animal» que puede sentir y prescribe como éticas todas aquellas acciones que están destinadas a resguardar los derechos de esos «alguienes» que sienten. De esta forma, podría reconocerse que el motor principal que impulsa al sensocentrismo es la empatía, entendida como la capacidad cognitiva de percibir, en un contexto común, lo que otro individuo puede sentir. A partir de este presupuesto se elaboran las teorías sobre derechos animales de las últimas décadas, y fundamentalmente las abolicionistas. Un ser sintiente es un ser con intereses, con preferencias y deseos. No necesita ser portador de características fisonómicas ni cognitivas similares a la de los humanos para ostentar el derecho inalienable a no ser usado como propiedad.

5. Los abolicionistas rechazan cualquier forma de discriminación humana, incluyendo el racismo, el sexismo, el heterosexismo, la discriminación por edad, 
el capacitismo o el clasismo, con el mismo énfasis con que rechazan el especismo. El especismo ha sido percibido como parte de un antropocentrismo o androcentrismo mucho más extenso, que igualmente discrimina a mujeres, minorías étnico-raciales o clases sociales bajas. Por ello, el especismo ha recibido importantes críticas desde posiciones feministas (Adams, 1991), o desde posiciones fuertemente opuestas a los sistemas de dominación capitalistas (Young, 1990). También la lucha contra el racismo ha señalado que, al igual que los argumentos prorracistas aceptan la existencia de un orden natural con razas superiores, el especismo plantea de forma paralela la existencia de una especie superior a la cual las demás quedan supeditadas (Spiegel, 1996). Puede, pues, afirmarse que las posturas especistas poco difieren de aquellas que justifican el racismo, el sexismo, la homofobia, el clasismo o el cognitivismo en el seno de la especie humana.

6. Los abolicionistas reconocen el principio de la no violencia. Ahora bien, eso no significa que la acción pacífica resulte condescendiente con el poder estatal y las políticas reformistas de los ejecutivos. Como igualmente afirma Steve Best: « La corriente crítica se opone a toda forma de discriminación, jerarquía y opresión, construyendo iniciativas radicales de transformación social, política y económica; apoya la desobediencia civil, la acción directa y el sabotaje económico y promueve, así mismo, políticas de alianza y unión con otros movimientos, con el objetivo de abrir caminos para una transformación estructural que libere la vida animal y el mundo natural de la colonización y la conquista de las elites dominantes» (Best, 2009).

En su In defense of animals. The Second Wave de 2005 , Peter Singer incluye todo un elenco de formas y acciones que configurarían el activismo animalista, y que irían desde la desobediencia civil, la acción de rescate y liberación animal directa, la defensa legal de los animales no humanos, las campañas en los medios o el boicot en el consumo. Henry Spira y el propio Singer terminan el volumen señalando algunas estrategias útiles para el activista en defensa de los derechos animales entre las que se encontrarían la necesidad de conectar con los pensamientos y preocupaciones de la ciudadanía en general, no resultar maniqueos en la división de buenos y malos, la búsqueda del diálogo con todas las partes implicadas o propuestas de planes realistas, si bien no descartan ir más allá de los cauces convencionales o los meros intentos de reforma legislativa (Singer y Spira, 2005).

La postura abolicionista para la consecución de los derechos animales es el rechazo último a la violencia. Es la afirmación última de la vida. Así, el movimiento de derechos animales habría de ser visto como la progresión lógica del movimiento pacifista, el cual pretende acabar con los conflictos entre humanos. El movimiento de derechos animales busca idealmente llevar ese paso más allá y acabar con los conflictos entre humanos y no-humanos (Francione, 2009). 


\section{A MODO DE CONCLUSIÓN}

En esta nota de investigación se han expuesto muchas de las teorías clásicas y más actuales en torno al debate sobre los derechos animales, destacando algunos elementos como los siguientes: qué entendemos por especismo y antiespecismo; hasta qué punto es posible conferir derechos a los animales no humanos y, sobre todo, qué posturas y debates encontramos en el seno del movimiento animalista, fundamentalmente entre los defensores del proteccionismo bienestarista para los no humanos y los partidarios de un enfoque abolicionista de la propiedad.

La filosofía antiespecista afirma que nos encontramos hoy día en el camino hacia un cambio de paradigma, la construcción de una nueva hegemonía no especista. De forma creciente afloran debates que no habían tenido apenas lugar antes y que se empiezan a establecer y consolidar en la esfera pública, desde la sociedad civil, los medios de comunicación o los parlamentos hasta el mundo académico, donde las disquisiciones no han dejado de crecer desde el último cuarto de siglo Xx. Los ordenamientos jurídicos de todo el mundo han ido incorporando medidas legales de protección animal que van desde la más frecuente protección o limitación del sufrimiento hasta proyectos como el del Gran Simio, que buscan trasladar parte de los derechos humanos a determinados primates. Las penas por maltratos se han intensificado y crece en la opinión pública una nueva sensibilidad al respecto.

Este giro animalista nos ha llevado a desenmascarar el especismo como concepción del mundo narrada desde una primacía humana. El especismo podría ser percibido, por tanto, como parte de un antropocentrismo o androcentrismo mucho más extenso, que igualmente discrimina a mujeres, minorías étnico-raciales o clases sociales bajas. Se trataría de un estigma más allá de la propia especie, pero con un funcionamiento similar, si bien reforzado, puesto que lo extraño, lo diferente son unas características diferenciadoras entre especies más que dentro de la misma especie.

Con el incremento en la intensidad y número de propuestas animalistas desde el ámbito académico han surgido igualmente disputas filosóficas y estratégicas en torno a las formas aceptables para definir nuestra relación con los no humanos. La diferenciación aquí planteada entre las propuestas bienestaristas y abolicionistas no solo calibran de forma cuantitativa el alcance de la protección animal sino, y sobre todo, de manera cualitativa. El eje central que separa ambas posiciones, como se ha querido presentar, es la nula permisividad entre los abolicionistas de la propiedad sobre otros (no humanos), frente al buen trato y el no abuso entre los bienestaristas.

A partir de todo lo anterior, la zoópolis que preconiza el antiespecismo, entendemos que necesariamente abolicionista, introduce la necesidad de concebir al resto de los animales con los que compartimos la polis, y de igual modo con quienes la convivencia es alejada, como miembros de pleno derecho de una comunidad mixta de humanos y no humanos, que participan en un proyecto cooperativo y comunitario, pero también personal e intransferible. Como plantea el lema del movimiento de liberación animal, el camino de la liberación animal es el camino de la liberación humana. 
Referencias

Adams, Carol. 1991. The Sexual Politics of Meat: A Feminist-Vegetarian Critical Theory. New York: Continuum.

Baltasar, Basilio (coord.). 2015. El derecho de los animales. Madrid: Marcial Pons.

Best, Steven. 2009. Moral Progress and Animal Liberation: The Struggle for Human Evolution. Lahham: Rowman and Littlefield.

Cavalieri, Paola. 2003. The Animal Question: Why Nonhuman Animals Deserve Human Rights. New York: Oxford University Press.

DeGrazia, David. 1996. Taking Animals Seriously: Mental Life and Moral Status. Cambridge: Cambridge University Press. Disponible en: http://dx.doi. org/10.1017/CBO9781139172967.

De Lora, Pablo. 2012. "La receta moral del vegetarianismo», en Jimena Rodríguez Carreño (ed.), Animales no humanos entre animales humanos. Madrid: Plaza y Valdés.

Donaldson, Sue y Will Kymlicka. 2011. Zoopolis. A Political Theory of Animal Rights. Oxford: Oxford University Press.

Francione, Gary. 1995. Animals, Property and the Law. Philadelphia: Temple University Press.

Francione, Gary. 2000. Introduction to Animal Rights: Your Child or the Dog? Philadelphia: Temple University Press.

Francione, Gary. 2009. Animals as Persons: Essays on the Abolition of Animal Explotation. New York: Columbia University Press.

Francione, Gary y Anna Charlton. 2013. Eat Like You Care: An Examination of the Morality of Eating Animals. New York: Create Space Independent Publishing Platform.

Francione, Gary y Anna Charlton. 2015. Animal Rights: The Abolitionist Approach. Exempla Press.

Francione, Gary y Robert Garner. 2010. The Animal Rights Debate. Abolition or Regulation? New York: Columbia University Press.

Frey, Raymond Gillespie. 1980. Interests and Rights: Case Against Animals. Oxford: Oxford University Press.

Goldman, Michael. 2001. "A Trascendental Defense of Speciesism», Journal of Value Inquiry, 33: 59-69. Disponible en: http://dx.doi.org/10.1023/A:1010387423499.

Gregory, James. 2007. Of Victorians and Vegetarians: The Vegetarian Movement in Nineteenth-century Britain. I.B. Tauris.

Herp, Blanca. 2008. Motivos para ser vegetariano. Barcelona: Océano.

Horta, Óscar. 2010. "What is Speciesism?», The Journal of Agricultural and Environmental Ethics, 23: 243-266. Disponible en: http://dx.doi.org/10.1007/s10806009-9205-2.

Joy, Melanie. 2013. Por qué amamos a los perros, nos comemos a los cerdos y nos vestimos con las vacas. Madrid: Plaza y Valdés. 
Klein, Naomi. 2015. Esto lo cambia todo. El capitalismo contra el clima. Barcelona: Paidós.

Lara, Francisco y Olga Campos. 2015. Sufre, luego importa. Reflexiones éticas sobre los animales. Madrid: Plaza y Valdés.

Leahy, Michael P. T. 1991. Against Liberation: Putting Animals in Perspective. Londres: Routledge.

Linzey, Andrew. 2009. Creatures of the Same God. Explorations in Animal Theology. Lantern Books.

Machan, Tibor R. 2004. Putting Human First. Why We are Nature's Favorite. Oxford: Rowman and Littlefield.

Nussbaum, Martha. 2005. Frontiers of Justice: Disability, Nationality, Species Membership. Cambridge: Harvard University Press.

Pérez, José María. 2012. «Evolución del marco jurídico de protección animal desde 1929 hasta 2010», en Jimena Rodríguez Carreño (ed.), Animales no humanos entre animales humanos. Madrid: Plaza y Valdés.

Perlo, Katherine Wills. (2009) Kinship and Killing: The Animal in World Religions. Columbia University Press. New York.

Pluhar, Evelyn B. 1995. Beyond Prejudice. The Moral Significance of Human and Nonbuman Animals. Durham: Duke University Press

Posner, Richard A. 2004. «Animal Rights: Legal, Philosophical and Pragmatical Perspectives», en Cass R. Sunstein y Martha Nussbaum (eds.), Animal Rights. Current Debates and New Directions. Oxford: Oxford University Press.

Regan, Tom. 1983. The Case for Animal Rights. Berkeley: University of California Press.

Regan, Tom. 2004. Jaulas Vacias. El desafío de los Derechos de los Animales. Barcelona: Altarriba.

Rollin, Bernard E. 1981. Animal Rights and Human Morality. Buffalo: Prometheus.

Ryder, Richard D. 2000. Animal Revolution: Changing Attitudes Towards Speciesism. Oxford: Berg Publishers.

Sapontzis, Steve. 1987. Morals, Reason, and Animals. Philadelphia: Temple University Press.

Singer, Peter. 1975. Animal Liberation: a New Ethics for our Treatment of Animals. New York: Random House.

Singer, Peter. (ed.) 2005. In Defense of Animals. The Second Wave. Oxford: Blackwell.

Singer, Peter y Jim Mason. 2006. The Ethics of What We Eat. Why our Food Choices Matter. Melbourne: Random House.

Spencer, Colin. 2000. Vegetarianism. A History. Londres: Grub Street.

Spiegel, Marjorie. 1996. The Dreaded Comparison: Human and Animal Slavery. New York: Mirror Books.

Waldau, Paul. 2011. Animal Rights. What Everyone Needs to Know. Oxford: Oxford University Press.

Wise, Steven M. 2000. Rattling the Cage: Toward Legal Rights for Animals. Cambridge: Perseus Books. 
Young, Iris Marion. 1990. Justice and the Politics of Difference. Princeton: Princeton University Press.

Young, Richard A. 1998. Is God a Vegetarian? Christianity, Vegetarianism, and Animal Rights. Chicago: Open Court Publishing Company.

Presentado para evaluación: 26 de septiembre de 2016.

Aceptado para publicación: 26 de octubre de 2016.

\section{RAFAEL VÁZQUEZ}

rvazquez@ugr.es

Es profesor de Teoría Política en el Departamento de Ciencia Política y de la Administración de la Universidad de Granada. Premio Nacional de Finalización de Estudios en Ciencia Política en 2001. Investigador visitante en varias universidades europeas (Florencia, Mannheim, London School of Economics and Political Science). Está especialmente interesado en el estudio de la sociedad civil (desde el asociacionismo cívico a la desobediencia civil), así como en otras cuestiones de teoría política, como la teoría política verde y el feminismo, los derechos animales y el antiespecismo, o la teoría política no occidental. Es autor de algunos libros y de varios artículos y capítulos de libros sobre las áreas mencionadas.

\section{ÁNGEL VALENCIA}

avalencia@uma.es

Es catedrático de Ciencia Política y de la Administración de la Universidad de Málaga. Su campo de investigación es la teoría política. En los últimos años su investigación se ha centrado, por un lado, en la teoría política verde, el análisis comparado de los movimientos y los partidos ecologistas y el estudio de las políticas medioambientales, desarrollando esta actividad en diversos grupos de investigación nacionales y, por otro, el malestar de la democracia, como resultado de los cambios de la cultura política y de la desafección democrática. Ha publicado numerosos artículos sobre estos temas en las principales revistas nacionales e internacionales, capítulos en libros colectivos y monográficos. Es asimismo autor de algunas monografías y varios libros como editor y coeditor, y también ha escrito capítulos en libros colectivos. 